\title{
Analysis on the Post-COVID-19 Fiscal Policy Based on the Empirical Analysis of Financial Revenue and Expenditure
}

\author{
Zhenlan Yao \\ School of Insurance and Economics, University of International Business and Economics, Beijing, China \\ Corresponding author's e-mail: Vivian.wang@cas-harbour.org
}

\begin{abstract}
The monthly data of China's national financial revenue and expenditure from January, 2012 to December, 2019 have been collected in this thesis. ADF Test, Johansen Test and Granger Test based on the monthly data have been investigated and the Error Correction Model have been set up. Results show that a long-term equilibrium exists in the national financial revenue and expenditure in the corresponding period from January 2012 to December 2019. When short-term fluctuations of fiscal revenue and expenditure deviating from the long-term equilibrium, the ECM Model could provide an adjustment at the rate of -0.3359 . The existence of the two-way causality between national financial expenditure and revenue implies that the series of fiscal policies focusing on tax-break and lowering cost issued since the Eighteenth National Congress of the CPC have provided an inner initiative in the growth of economic growth, resulting in positive effects on stimulating the growth of national economy and increasing the national financial revenue to certain extent. To restart the economy restrained by the COVID-19, it would be effective to issue the fiscal policy concerning an increase in financial expenditure.

Keywords: financial revenue and expenditure, empirical analysis, COVID-19, fiscal policy, Error Correction Model (ECM), Granger Test, Augmented Dicky-Fuller (ADF) Test
\end{abstract}

\section{INTRODUCTION}

With great consideration attached to the safety and health for the people, Chinese government and the Communist Party have taken closed-up measurements on residential and concentrated commercial areas since the outbreak of COVID-19. As a result of the global dispersion of the pandemic, international trading have been facing adverse conditions as well. According to data released by the National Bureau of Statistics on April 17, China's gross domestic product only reached 20650.4 billion Yuan in the first quarter of 2020, revealing an annual decrease of $6.8 \%$ based on fixed price. Moreover in the National People's Congress and the Chinese Political Consultative Conference (NPC\&CPCC) on May 22, 2020, Premier Li Keqiang stressed on canceling the settlement of Chinese GDP growth rate target. Hence, with the severe difficulties Chinese economic growth face in 2020 , the fiscal revenue is bound to decrease significantly. To tackle the crises and cushion its impact, and furthermore achieving economic recovery, this article is intended to discuss financial policy-making under COVID-19 based on empirical analysis of fiscal revenue and expenditure, adopting methods include generating Error Correction Model based on

\section{LITERATURE REVIEW}

Although COVID-19 pandemics have proposed challenges on economy and policy and made a brand-new circumstance, there could be reference on methodologies of overcoming the fiscal dilemma from a global perspective. According to McConnell, tracing from the Great Depression of the 1930s, 'emergency workers' were employed by the Federal Government under the especially created Works Progress Administration (WPA), and became an important part of the economic recovery [13]. Though civilian works programs include considering new recruits to the military following the US entry into World War II may not be appropriate to be replicated directly in the plight of the Great Recession of 2008, new forms of WPA aimed at breaking the dilemma of labor force participation rate due to effects of the recession on employment prospects could be considered, which fundamentally substituted an increase in fiscal expenditure.

Alari Paulusa, Francesco Figarib and Holly Sutherlanda confirmed the effectiveness of expansionary policies aimed at fiscal expenditure on the other side of the shield, focusing on the austerity measures introduced in the wake of the financial and economic crisis in the late 2000s [11]. Their results show that combined cuts in public wages and transfers are more likely to affect liquidity constrained households and thereby aggregate demand, while richer 
households tend to bear a greater burden in most countries. Effects of combined cuts in public wages and transfers casted on liquidity-constrained households were proved to be detrimental for aggregate demand, influencing the proceeding of economic recovery [11].

Especially for the circumstance of COVID-19, as historian Walter Scheidel has written, pandemics represent one of the 'four horsemen' of the apocalypse, capable of generating, through their violent levelling processes, temporary redistributions of income and the mitigation of inequality. Though the impact of COVID-19 on inequality is still far from clear, based on the research carried out by Shaun Wilson on the state of affairs in Australia, expanding welfare generosity and providing government support for private employment through wage subsidies have been proved to be effective, which are intrinsically equivalent to increasing fiscal expenditure [12].

Up to now, there are mainly four types of hypotheses that Chinese scholars have projected on the relationship between fiscal revenue and expenditure, including 'make both ends meet', which indicates that the alteration of fiscal revenue would correspondingly set off the fluctuation in fiscal expenditure; also the hypothesis of 'spend and tax', where the expenditure is believed to be the decisive factor of fiscal revenue; 'fiscal synchronization' hypothesis considers the fiscal revenue and expenditure depend on and influence each other, while 'separation of institutions' hypothesis holds that no causal relationship exists between the two factors. Adopting co-integration test and Error Correction Model, Chang et.al carried out research based on fiscal revenue and expenditure data for decades since the founding of People's Republic of China [2]. They have discovered that the long-term equilibrium did exist [2]. Furthermore, fiscal revenue is the Granger Cause of fiscal expenditure [2]. While Chung et.al discovered that fiscal expenditure in Jiangxi Province is the Granger Cause of corresponding fiscal revenue [3]. Using econometrics methods, Liu focused on Anhui Province and the empirical analysis suggested the existence of a long-term equilibrium between its fiscal revenue and expenditure, while fiscal expenditure acted as the cause of fluctuation in revenue [1].

Overall, as the scholars have revealed the importance of increasing fiscal expenditure in changing economic situation and realizing recovery by common consent, yet they have diverse opinions on the relationship between fiscal revenue and expenditure. As the two interweaves tightly with economic growth and has significantly influence over each other. Furthermore, according to Huang et.al, inharmonious development of fiscal revenue and expenditure will undoubtedly aggravate the financial risk and restrict economic growth [4]. Based on the empirical analysis carried out on the development of financial industry in Guizhou Province, Feng discovered that although increasing government expenditure hadn't posed a significant impact on the financial sector, it did have a positive effect in the long term [5]. Wang compared the fiscal balance of Guizhou Province with Guangxi Province and pointed out the remarkable growth rate of GDP in Guizhou Province which have ranked top 3 in the past consecutive 7 years is mainly profited by the prominent scale of fiscal expenditure which attained to $25 \%$ of the province GDP and even reaching more than $35 \%$ since 2010, showing the role of fiscal revenue and expenditure as stabilizer and accelerator [6].

The government's support for a stable growth and promotion of supply side structural reform has led to a rigid increase in fiscal expenditure; however, the current epidemic situation has cast great downward pressure on the economy and weakened the growth of fiscal revenue. Since the 18th National Congress of the Communist Party of China, a series of measures have taken place in order to reduce taxes and ensure the development of the people's livelihood. As a result, this paper selects the monthly data of national fiscal revenue and expenditure from January 2012 to December 2019 for empirical analysis, in order to determine the impact of the series of fiscal measures carried out, and attempts to put forward suggestions on the formulation of corresponding financial policies for economic recovery in the post-epidemic era.

\section{DATA SOURCE}

Discussion in this paper is based on a total of 96 sets of observation consisting CZSR (fiscal revenue) and CZZC (fiscal expenditure) dating from January 2012 to December 2019, collected from the Database of University of International Business and Economics - Research and Application Platform of Chinese Macroeconomics Monthly Statistics - Fiscal Revenue and Expenditure.

\section{MODEL ESTABLISHMENT AND VERIFICATION}

\subsection{Stationary test of data series}

While the high relevance between explained variable and explanatory variable is only due to their same trend of fluctuation in the passage of time instead of real inter correlation, non-stationary data in time series modeling may lead to pseudo regression problem. To ensure that neither a random trend nor deterministic trend exist, this article adopts Aggregated Dicky-Fuller method to test the stability of the fiscal revenue (CZSR) and expenditure (CZZC) series data. The null hypothesis H0 of ADF test is that the series have unit root, results shown in Table 1 below.

Results of ADF Test in Table 1 indicate both the original and 1 st difference series are not significant under $5 \%$ level, leading to accept the null hypothesis that the series have unit roots. However, 2nd difference of CZSR and CZZC series shown that the original series are integrated of order 2 . Based on the hypothesis of significance test, only the 2nd difference series meet the premise of a co-integration test. 
Table 1 Test results of stationarity of data series

\begin{tabular}{|l|c|c|c|c|c|c|}
\hline sequence type & variable & ADF value & $5 \%$ critical value & significance & test result & conclusion \\
\hline \multirow{2}{*}{ original series } & CZSR & 6.1712 & -3.4642 & 1.0000 & H0 Not Rejected & non-stationary \\
\cline { 2 - 7 } & CZZC & 5.4368 & -3.4642 & 1.0000 & H0 Not Rejected & non-stationary \\
\hline \multirow{2}{*}{$1^{\text {st }}$ difference } & CZSR & -3.4102 & -3.4649 & 0.0569 & H0 Not Rejected & non-stationary \\
\cline { 2 - 7 } & CZZC & -2.2124 & -3.4649 & 0.4743 & H0 Not Rejected & non-stationary \\
\hline \multirow{2}{*}{$2^{\text {nd }}$ difference } & CZSR & -164.0076 & -1.9448 & 0.0000 & H0 Rejected & stationary \\
\cline { 2 - 7 } & CZZC & -98.0532 & -1.9448 & 0.0000 & H0 Rejected & stationary \\
\hline
\end{tabular}

\subsection{Johansen System Cointegration Test}

Co-integration refers to the common random trend existing among multiple sequences. Accordingly, co-integration test is applied to determine whether a pseudo regression exist in the regression function generated based on non-stationary series, and to test whether a linear combination of a group of non-stationary series has reached stable equilibrium. In this session Johansen System Co-integration Test would be applied to determine the existence of long-term stationary relationship between the variable series fiscal revenue CZSR and fiscal expenditure CZZC. Conduct stationary test focusing on the two series with lag interval $(2,2)$ with the following results shown in Table 2:

Table 2 Trace test for eigenvalues of Johansen statistic

\begin{tabular}{|c|c|c|c|c|c|}
\hline Null Hypothesis & eigenvalue & trace statistic & $5 \%$ critical value & p-value & conclusion \\
\hline None & 0.3851 & 45.6231 & 15.4947 & 0.0000 & H0 Rejected \\
\hline At most 1 & 0.0042 & 0.3927 & 3.8415 & 0.5309 & H0 Not Rejected \\
\hline
\end{tabular}

Table 3 Johansen maximum eigenvalue test results

\begin{tabular}{|l|c|c|c|c|c|}
\hline Null Hypothesis & Eigenvalue & Eigenvalue statistic & $5 \%$ critical value & p-value & conclusion \\
\hline None & 0.3851 & 45.2304 & 14.2646 & 0.0000 & H0 Rejected \\
\hline At most 1 & 0.0042 & 0.3927 & 3.8415 & 0.5309 & H0 Not Rejected \\
\hline
\end{tabular}

From Table 2 and Table 3, it can be seen that under significance level of 0.05 , the results of both of the trace test and maximum eigenvalue of Johansen Test are rejecting the null hypothesis that there is no stable relationship between fiscal revenue CZSR and fiscal expenditure CZZC, but not reject the hypothesis that at least one stationary relationship exist. Overall, it can be concluded that there is a long-term stationary equilibrium between fiscal revenue and expenditure.

\subsection{Establishment of Error Correction Model (ECM)}

Ordinary Least Square (OLS) linear regression between the 1st difference variable series $\Delta \mathrm{SR}$ and $\Delta \mathrm{ZC}$ is performed. Results are shown in Table 4 below:

Table 4 Results of error correction test

\begin{tabular}{|c|c|c|c|c|c|c|}
\hline Variable & Coefficient & Standard Error & Student-t stat & p-value & $\mathrm{R}^{2}$ & Adjusted R $^{2}$ \\
\cline { 1 - 4 }$\Delta \mathrm{ZC}$ & 0.8185 & 0.0104 & 78.4303 & 0.0000 & \multirow{2}{*}{0.9858} & \multirow{2}{*}{0.9856} \\
\cline { 1 - 4 } $\mathrm{ECM}_{\mathrm{t}-1}$ & -0.3359 & 0.0879 & -3.8205 & 0.0002 & & \\
\hline
\end{tabular}

An Error Correction Model $\Delta \mathrm{SR}=0.8185^{*} \Delta \mathrm{ZC}-0.3359 *$

ECMt-1+عt could be set up based on the regression results shown in Table 4, where the coefficients are all significant under $1 \%$ degree of confidence, while as DW stat $=1.8318$ falls in non-autocorrelation interval indicating no existence 
of missing variables. As the estimated coefficient of the error correction term is $-0.3359<0$, which is significant under $1 \%$ degree of confidence, it could be concluded that the fluctuation in the level of fiscal revenue is affected by the error in the previous period, while the present fluctuation of fiscal expenditure has significant influence on fiscal revenue of the same period. Based on the absolute value of the regression coefficient, we can infer that the current fluctuation of fiscal expenditure has a great adjustment range to the fiscal revenue with the coefficient up to 0.8185 . However, as the unit adjustment ration is only -0.3359 . it is revealed that the adjustment range of the error in the previous period to the current fluctuation of fiscal revenue is relatively small.
The test above shows that a long-term stable cointegration relationship exists between fiscal revenue and expenditure, which meets the basic premise to carry out a Granger Test to empirically analyze the causality between the two variables.

\subsection{Granger Casualty Test}

From the results of stationarity test above, CZSR and CZZC sequences are non-stationary and can only be stabilized after the second-order difference. Therefore, the stationary difference sequences D2SR and D2ZC are applied in this part for the Granger test. Based on the test result in Table 5, it can be concluded that a reciprocal causation is involved in the pair of variables D2ZC and D2SR.

Table 5 Results of the Granger Test

\begin{tabular}{|l|c|c|c|c|c|}
\hline \multicolumn{1}{|c|}{ Null Hypothesis } & lags & & F stat & p-value & Conclusion \\
\hline D2ZC does not Granger cause D2SR & 1 & 93 & 16.0168 & 0.0001 & Reject H0 \\
\hline D2SR does not Granger cause D2ZC & 1 & 93 & 15.0957 & 0.0002 & Reject H0 \\
\hline D2ZC does not Granger cause D2SR & 2 & 92 & 25.6723 & $2 . E-09$ & Reject H0 \\
\hline D2SR does not Granger cause D2ZC & 2 & 92 & 32.2383 & 3.E-11 & Reject H0 \\
\hline
\end{tabular}

\section{CONCLUSION AND SUGGESTION}

The monthly data of national fiscal revenue and expenditure from January 2012 to December 2019 have been collected in the thesis, where the relationship between national fiscal revenue and expenditure are discussed using co-integration test and error correction model. The conclusions are drawn as follows:

Firstly, the Granger Causality Test using the national fiscal revenue and expenditure data from January 2012 to December 2019 shows that a reciprocal causation is involved in the pair of variables, which differs from that of the relevant literature. The reason for that may lay in the data used in this research, because a series of tax and fee reduction measures have been taken after the 18th National Congress of the Communist Party of China. Hence, compared with that before, the national fiscal revenue has been internalized into fiscal expenditure resulting in benefiting the people, forming an endogenous force for economic growth, and mobilizing the enthusiasm and subjective initiative of the people's labor.

Secondly, the ECM model set up in this article is $\Delta$ $\mathrm{SR}=0.8185^{*} \Delta \mathrm{ZC}-0.3359 *$ ECMt $-1+\varepsilon \mathrm{t}$, with its DW stat located in non-autocorrelation interval, which indicated that no missing variables exist in the original model. Also, as the estimated error correction coefficient is negative (-0.3359) and significant under $1 \%$ level of confidence, it could be interpreted that fluctuations in fiscal revenue could be affected by the error in the previous period, while current wave in fiscal expenditure could pose significant impact on that of fiscal revenue. Therefore, increasing fiscal expenditure and reducing fiscal revenue are conducive to the rise of future fiscal revenue. Guo et.al (2018) [7] adopted $\mathrm{H}-\mathrm{P}$ filter to estimate the potential and gap of Chinese output, analyze the causal relationship between fiscal policy formulation and correspond economic fluctuations by establishing a VAR model with impulse response function and decomposition of variance. Their discovery showed that asymmetry exists in the causal relationship between fiscal policies focusing on revenues and economic fluctuations, while fiscal policies, especially the portion concentrating on expenditures, are not sensitive in reaction to the fluctuations. Therefore, in coping with economic downward fluctuations under the circumstance of epidemic, the more aggressive fiscal expenditure is not likely to pose a negative impact on the current economic situation.In contrast, it can be in favor of stabilizing economic fluctuations and stimulating future recovery.

\section{ACKNOWLEDGMENT}

I would like to express my gratitude to all those who helped me during the writing of the thesis. I gratefully acknowledge the help of Professor Yanlin $\mathrm{He}$ from University of International Business and Economics. Also, I would like to thank Professor Tim Nguyen from Johns Hopkins University and Professor Guido Ascari from Oxford University for patience, encouragement, and professional instructions. My gratitude also 
extends to my family for constant assistance and care.

\section{REFERENCES}

[1] Y. Liu. An Empirical Study on the Relationship Between Fiscal Revenue and Expenditure in Anhui Province From 1980 To 2012, Business, 2016(3): 171

[2] H. Chang \& H.F. Zhao. An Empirical Analysis of the Long-Term Equilibrium of Fiscal Revenue and Expenditure in China. Journal of Zhongnan University of Economics and Law, 2004(6): 66-73.

[3] L.H. Chung L. Xu, \& D.L. Chou. Public Service in Jiangxi Province Under the Perspective of Fiscal Revenue and Expenditure. Journal of Jiangxi Finance College, 2015(5): 8-53

[4] F.Y. Huang, \& G.Y. Han. Time varying nonlinear characteristics between fiscal revenue and expenditure in China. Inquiry into Economic Issues, 2018(12): 135-142

[5] M.C. Feng. Empirical Analysis of the Interactions Between Fiscal Balance and The Development of Financial Industry -- Taking Guizhou Province as an Example. Journal of Guiyang University (Social Sciences), 2016(5): 64-68

[6] J.D. Wang. A Comparative Study of Fiscal Revenue and Expenditure in Guizhou and Guangxi Province and its Policy Implications, Guangxi Ethnic Studies, 2019(4): 124-135

[7] W. Guo, J.H. Cao, \& L.P. Cheng. An empirical study on the relationship between economic fluctuation and fiscal policy in China, Modern Management Science, 2018(3): 12-15

[8] COVID-19- Consumer Law Research Group. Consumer Law and Policy Relating to Change of Circumstances Due to the COVID-19 Pandemic. Journal of Consumer Policy, 2020(43): 437 - 450

[9] G. Fenz, C. Ragacs, M. Schneider, \& K. Vondra. COVID-19-induced recession: biggest economic policy challenge for Austria in the "Second Republic". Monetary Policy \& The Economy, 2020(20): 213-252

[10] H. Bargawi, \& G. Cozzi. Engendering Economic Recovery: Modeling Alternatives to Austerity in Europe. Feminist Economics, 2017(23): 225 - 249
[11] A. Paulus, F. Figari, \& H. Sutherland. The design of fiscal consolidation measures in the European Union: distributional effects and implications for macro-economic recovery. Oxford Economic Papers, 2017, 69(3): $632-654$

[12] S. Wilson. Rising Pressures, New Scaffolding, Uncertain Futures: Australia's Social Policy Response to the Covid-19 Pandemic. Journal of Australian Political Economy,2020(85): 183-92

[13] S. L.B. McConnell. WPA for Today: Can the US Afford Economic Recovery? Journal of Economic Issues, 2014, XLVIII (2):541-552 